\title{
Is being small for gestational age at birth a predictive risk factor for retinopathy of prematurity? A study in Central Maharashtra, India
}

\author{
Snehal Rhishikesh Thakre (D), Pradnya Ashish Deshmukh, Pritesh Jatinbhai Desai, \\ Jyotika Prasanna Mishrikotkar
}

MGM Medical College, Aurangabad, India

\begin{abstract}
BACKGROUND: Retinopathy of prematurity (ROP) is a leading cause of avoidable blindness in preterm infants. Born preterm with small gestation age (SGA) may be an additional risk factor for developing ROP. The study was conducted to evaluate the incidence, risk factors, and severity of ROP in SGA newborns admitted to the newborn nursery. MATERIALS AND METHODS: 91 preterm infants were screened for ROP in a prospective observational study conducted in a teaching hospital in central Maharashtra, India using the National Neonatology Forum of India criteria (NNF, 2010). Systemic risk factors and ocular findings were documented. The incidence, risk factors, and severity of ROP were compared between the SGA and appropriate for gestational age (AGA) newborns.

RESULTS: The incidence of ROP was 36.26\% (total), 39.62\% (SGA), and 31.57\% (AGA) amongst screened infants. ROP was more common in babies with higher gestational age (35.4 weeks; $\mathrm{p}=0.064$ ) in the SGA group, and it was more in babies with lesser gestational age ( 32.2 weeks; $\mathrm{p}=0.033)$ in the AGA group. There was no difference in the risk factors between the two groups on univariate and multivariate analysis.

CONCLUSIONS: The incidence of ROP was higher in SGA infants than AGA infants in the present study. However, there was no difference in the risk factors and severity of ROP between the two groups.
\end{abstract}

KEY WORDS: retinopathy of prematurity; small gestation age (SGA); appropriate for gestational age (AGA)

Ophthalmol J 2021; Vol. 6, 83-88

\section{INTRODUCTION}

Retinopathy of prematurity is a significant cause of avoidable blindness in children [1]. In particular, India is experiencing the third epidemic of blindness due to ROP [2]. It is projected that approximately 18,000 infants will go blind every year in India due to ROP [3]
Retinopathy of prematurity occurs in infants with low gestational age (GA) and low birth weight (BW). However, infants with comparatively higher gestational age and higher birth weight in developing countries like India also develop ROP [4-6].

Along with low birth weight and low gestational age, respiratory distress syndrome, unregulated use 
of oxygen, chronic lung disease, fetal hemorrhage, sepsis, transfusion of blood products, patent ductus arteriosus are some of the other significant risk factors which play an essential role in the development of ROP $[7,8]$. Studies have shown that SGA may contribute to the above long list of risk factors [8-10]. The present study was conducted to evaluate the incidence, risk factors, and severity of ROP in SGA infants.

\section{MATERIAL AND METHODS}

This prospective observational study was conducted in a teaching hospital in central Maharashtra, India, between December 2015 and July 2018. The study was approved by the institutional ethics committee and adhered to the guidelines of the Declaration of Helsinki. Informed consent was obtained from parents of all neonates included in the study.

\section{Inclusion criteria}

Inclusion criteria were as follows:

- preterm neonates with $\leq 34$ weeks of gestational age and/or birth weight $\leq 1750 \mathrm{~g}$;

- preterm neonates with 34-36 weeks of gestational age and/or birth weight between 1751 and $2000 \mathrm{~g}$ who are at a high risk of developing ROP with risk factors such as the need for cardiorespiratory support or prolonged oxygen therapy, blood transfusion, apnea of prematurity, anemia requiring blood transfusion, or neonatal sepsis

OR

- any neonate believed at risk of ROP by the attending pediatrician.

\section{Exclusion criteria}

Neonates who died before complete vascularization of the retina or lost to follow-up were excluded from the study.

\section{Study procedure}

A total of 91 preterm neonates meeting the screening criterion during the study period were included. The screening was performed by a pediatric ophthalmologist and or a retina specialist in the neonatal intensive care unit (NICU). The first screening was conducted between the 20th and 30th days of life. Pupils were dilated with $0.4 \%$ tropicamide, and $2.5 \%$ phenylephrine eye drops instilled twice at an interval of 10 minutes. A third drop was instilled if the pupil was not sufficiently dilated. The retinal screening was performed using an indirect ophthalmoscope with a 20D lens under topical anesthesia and monitoring vital signs. A pediatric speculum with scleral depression was used to examine the retina. The screening was carried out until:

1 - complete retinal vascularization;

2 - regression of ROP was noted with complete retinal vascularization, or

3 - zone-III retinal vascularization was attained without previous zone I or II ROP.

Systemic risk factors and ocular findings were documented. Retinopathy of prematurity was classified according to the International Classification of ROP (ICROP). All the preterm neonates included in the study were further subdivided into two categories - appropriate for gestational age (AGA) and small for gestational age (SGA) using Fenton's Criteria [12]. Weight, head circumference, and length of the neonate were marked on specific separate charts for girls and boys.

All babies diagnosed with type 1 ROP were treated as per early treatment of ROP protocol (ETROP ), while those with aggressive posterior ROP (APROP) were treated with intravitreal anti-VEGF agents after taking informed consent. Statistical analysis

Collected data was compiled in an MS Excel sheet. The collected data were analyzed with statistical packages for social science v.20 (SPSS). Quantitative data are represented in the form of mean and standard deviation. Odds ratio, univariate analysis, and chi-square test were applied to assess the significant association between risk factors and ROP development. Multivariate analysis was applied to check significant risk factors development of ROP. P-value was checked at a 5\% level of significance.

\section{RESULTS}

Ninety-one preterm neonates met the screening criteria in the study. Of these, $53(58.24 \%)$ were SGA, and 38 (41.75\%) were AGA infants. 36.26\% (33 out of 91) developed ROP. The incidence of ROP in the SGA group was $39.62 \%$ (21 out of 53 ) and $31.57 \%$ (12 out of 38 ) in the AGA group. This was statistically significant $(\mathrm{X} 2=0.61 ; \mathrm{DF}=1$; $\mathrm{p}=0.043 ; \mathrm{p}<0.05$ )

Retinopathy of prematurity was observed in babies with higher gestational age (35.4 weeks; $\mathrm{p}=0.064)$ in the SGA group as compared to the 


\begin{tabular}{|c|c|c|c|c|c|c|c|}
\hline \multirow{2}{*}{ GA [weeks] } & \multirow{2}{*}{ ROP positive } & \multirow{2}{*}{ ROP negative } & \multirow{2}{*}{ Total } & \multicolumn{2}{|c|}{ Mean GA } & \multirow{2}{*}{ T-value } & \multirow{2}{*}{ p-value } \\
\hline & & & & ROP positive & ROP negative & & \\
\hline \multicolumn{8}{|l|}{ SGA } \\
\hline$<30$ & 02 & 01 & 03 & \multirow{4}{*}{35.4} & \multirow{4}{*}{34.2} & \multirow{4}{*}{3.14} & \multirow{4}{*}{$\begin{array}{c}0.064 \\
\text { NS }\end{array}$} \\
\hline $30-34$ & 09 & 14 & 23 & & & & \\
\hline$>34$ & 11 & 16 & 27 & & & & \\
\hline Total & 21 & 32 & 53 & & & & \\
\hline \multicolumn{8}{|l|}{ AGA } \\
\hline$<30$ & 06 & 01 & 07 & \multirow{4}{*}{32.2} & \multirow{4}{*}{36.6} & \multirow{4}{*}{3.14} & \multirow{4}{*}{$\begin{array}{c}0.033 \\
S\end{array}$} \\
\hline $30-34$ & 04 & 13 & 17 & & & & \\
\hline$>34$ & 02 & 12 & 14 & & & & \\
\hline Total & 12 & 26 & 38 & & & & \\
\hline
\end{tabular}

NS - non significant

AGA group, and it was more in babies with lesser gestational age (32.2 weeks; $\mathrm{p}=0.033$ ) (Tab. 1). The mean birth weight was lower amongst ROP positive babies $(1207.11 \pm 19.21$ grams in the AGA group and $1412.11 \pm 21.92$ grams in the SGA group) as compared to non-ROP babies $(1712.11 \pm 21.92 \mathrm{~g}$ in the AGA group and $1680.11 \pm 19.21 \mathrm{~g}$ in the SGA group) in both groups ( $p=0.043$ for the AGA group and $\mathrm{p}=0.048$ for the SGA group) (Tab. 2).

Type $1 \mathrm{ROP}$ as per the ETROP classification occurred in $10.98 \%$ (10/91 preterm neonates). The incidence of type 1 ROP in SGA and AGA groups was $33.3 \%$ and $25 \%$, respectively, with $7 / 21$ babies in the SGA group and $3 / 12$ babies in the AGA group having treatable ROP but was not statistically significant. Of the seven babies with type 1 ROP in the SGA group, 2 had aggressive posterior ROP (APROP).

On univariate analysis, the risk factors for ROP development in both the SGA and AGA groups were similar (Tab. 3).

On multivariate analysis, blood transfusion was identified as a risk factor for the SGA group only (Tab. 4, 5).

\section{DISCUSSION}

In addition to prematurity, SGA infants are a high-risk population, being vulnerable due to many causes for developing ROP. All babies with weight less than 2000 grams irrespective of their gestational age at birth are screened routinely for ROP at our institute. Our study attempts to

Table 2. Incidence of retinopathy of prematurity (ROP) according to birth weight (BW) in neonates with small gestation age (SGA) and appropriate for gestational age (AGA)

\begin{tabular}{|c|c|c|c|c|c|c|c|}
\hline \multirow{2}{*}{ BW [g] } & \multirow{2}{*}{ ROP positive } & \multirow{2}{*}{ ROP negative } & \multirow{2}{*}{ Total } & \multicolumn{2}{|c|}{ Mean BW } & \multirow{2}{*}{ T-value } & \multirow{2}{*}{ p-value } \\
\hline & & & & ROP positive & ROP negative & & \\
\hline \multicolumn{8}{|l|}{ SGA } \\
\hline$<1000$ & 01 & 04 & 04 & \multirow{4}{*}{$1412.11 \pm 21.92$} & \multirow{4}{*}{$1680.11 \pm 19.21$} & \multirow{4}{*}{2.46} & \multirow{4}{*}{$\begin{array}{c}0.048 \\
S\end{array}$} \\
\hline $1000-1750$ & 12 & 16 & 28 & & & & \\
\hline$>1750$ & 08 & 12 & 20 & & & & \\
\hline Total & 21 & 32 & 53 & & & & \\
\hline \multicolumn{8}{|l|}{ AGA } \\
\hline$<1000$ & 03 & 00 & 03 & \multirow{4}{*}{$1207.11 \pm 19.2$} & \multirow{4}{*}{$1712.11 \pm 21.92$} & \multirow{4}{*}{2.64} & \multirow{4}{*}{$\begin{array}{c}0.043 \\
S\end{array}$} \\
\hline $1000-1750$ & 06 & 07 & 13 & & & & \\
\hline$>1750$ & 03 & 19 & 22 & & & & \\
\hline Total & 12 & 26 & 38 & & & & \\
\hline
\end{tabular}


Table 3. Univariate analysis of fetal risk factors for retinopathy of prematurity (ROP) in in neonates with small gestation age (SGA) and appropriate for gestational age (AGA)

\begin{tabular}{|l|c|c|c|c|c|c|}
\hline & \multicolumn{2}{|c|}{ SGA babies with ROP } & \multirow{2}{*}{ p-value } & \multicolumn{2}{c|}{ AGA babies with ROP } & \multirow{2}{*}{ p-value } \\
\cline { 1 - 1 } & Present & Absent & & Present & Absent & \\
\hline Multiple pregnancy & $6 / 21$ & $15 / 21$ & 0.03 & $5 / 12$ & $7 / 12$ & 0.041 \\
\hline Eclampsia & $3 / 21$ & $18 / 21$ & 0.07 & $2 / 12$ & $10 / 12$ & 0.08 \\
\hline RDS & $5 / 21$ & $16 / 21$ & 0.043 & $9 / 12$ & $3 / 12$ & 0.003 \\
\hline Apnoic spell & $2 / 21$ & $19 / 21$ & 0.071 & $3 / 12$ & $9 / 12$ & 0.073 \\
\hline$O_{2}$ supplementation & $14 / 21$ & $7 / 21$ & 0.001 & $7 / 12$ & $5 / 12$ & 0.01 \\
\hline Ventilation & $3 / 21$ & $18 / 21$ & 0.07 & $2 / 12$ & $10 / 12$ & 0.08 \\
\hline Sepsis & $7 / 21$ & $14 / 21$ & 0.04 & $4 / 12$ & $8 / 12$ & 0.047 \\
\hline Intraventricular hemorrhage & $00 / 21$ & $21 / 21$ & - & $1 / 12$ & $11 / 12$ & 0.10 \\
\hline Blood transfusion & $8 / 21$ & $13 / 21$ & 0.02 & $4 / 12$ & $8 / 12$ & 0.047 \\
\hline Fetal distress & $3 / 21$ & $18 / 21$ & 0.07 & $3 / 12$ & $9 / 12$ & 0.073 \\
\hline Phototherapy & $2 / 21$ & $19 / 21$ & 0.071 & $1 / 12$ & $11 / 12$ & 0.10 \\
\hline Surfactant administration & $3 / 21$ & $18 / 21$ & 0.07 & $1 / 12$ & $11 / 12$ & 0.10 \\
\hline Congenital heart disease & $00 / 21$ & $21 / 21$ & - & $1 / 12$ & $11 / 12$ & 0.10 \\
\hline Anemia & $5 / 21$ & $16 / 21$ & 0.043 & $4 / 12$ & $8 / 12$ & 0.047 \\
\hline Thrombocytopenia & $2 / 21$ & $19 / 21$ & 0.071 & $1 / 12$ & $11 / 12$ & 0.10 \\
\hline Neonatal jaundice & $00 / 21$ & $21 / 21$ & - & $2 / 12$ & $10 / 12$ & 0.08 \\
\hline Hypoglycemia & $1 / 21$ & $20 / 21$ & 0.09 & $00 / 12$ & $12 / 12$ & - \\
\hline
\end{tabular}

RDS — respiratory distress syndrome

Table 4. Multivariate analysis of fetal risk factors for retinopathy of prematurity (ROP) in neonates with small gestation age (SGA)

\begin{tabular}{|c|c|c|c|c|c|c|c|}
\hline \multirow{2}{*}{ Variables } & \multirow{2}{*}{$\beta$} & \multirow{2}{*}{ SE } & \multirow{2}{*}{ Wald } & \multirow{2}{*}{$\mathrm{p}$-value } & \multirow{2}{*}{$\mathbf{O R}$} & \multicolumn{2}{|c|}{$95 \% \mathrm{Cl}$ for OR } \\
\hline & & & & & & Lower & Upper \\
\hline Gestational age & 1.341 & 0.311 & 7.631 & 0.005 & 2.131 & 1.009 & 3.617 \\
\hline Birth weight & 1.712 & 0.183 & 6.542 & 0.002 & 3.111 & 1.213 & 4.124 \\
\hline Multiple pregnancy & 1.612 & 0.256 & 9.219 & 0.006 & 1.354 & 1.004 & 2.871 \\
\hline Eclampsia & 0.256 & 0.277 & 0.857 & 0.354 & 0.774 & 0.450 & 1.331 \\
\hline Sepsis & 2.394 & 0.315 & 2.560 & 0.002 & 2.483 & 1.799 & 3.752 \\
\hline RDS & 0.935 & 0.284 & 10.822 & 0.001 & 1.393 & 1.093 & 2.685 \\
\hline $\mathrm{O}_{2}$ supplementation & 1.921 & 0.265 & 52.597 & 0.000 & 6.380 & 4.063 & 11.479 \\
\hline Fetal distress & 1.264 & 0.243 & 27.160 & 0.000 & 3.540 & 2.201 & 5.695 \\
\hline Phototherapy & 0.252 & 0.260 & 0.943 & 0.332 & 1.287 & 0.773 & 2.141 \\
\hline Ventilation & 0.274 & 0.341 & 2.912 & 0.041 & 1.023 & 1.007 & 2.411 \\
\hline Blood transfusion & 1.256 & 0.277 & 1.857 & 0.004 & 0.774 & 0.450 & 1.331 \\
\hline Surfactant & 1.612 & 0.191 & 0.219 & 0.053 & 0.854 & 0.704 & 2.112 \\
\hline Anaemia & 1.254 & 0.5511 & 12.781 & 0.000 & 1.672 & 1.016 & 2.114 \\
\hline Thrombocytopenia & 0.462 & 0.234 & 0.982 & 0.056 & 0.891 & 0.678 & 1.412 \\
\hline Hypoglycemia & 0.256 & 0.277 & 0.857 & 0.354 & 0.774 & 0.450 & 1.331 \\
\hline
\end{tabular}

$\mathrm{p}<0.05$ = statistically significant; $\mathrm{RDS}$ - respiratory distress syndrome; $\mathrm{SE}$ - standard error; $\mathrm{OR}$ - odds ratio; $\mathrm{Cl}$ - confidence interval

assess any difference in the incidence, risk factors, and severity of ROP amongst the AGA and SGA infants.
The overall incidence of ROP in our study was $36.26 \%$. Our results are similar to the current trends [15-18] in developing countries. The incidence of 


\begin{tabular}{|c|c|c|c|c|c|c|c|}
\hline \multirow{2}{*}{ Variables } & \multirow{2}{*}{$\beta$} & \multirow{2}{*}{ SE } & \multirow{2}{*}{ Wald } & \multirow{2}{*}{ p-value } & \multirow{2}{*}{ OR } & \multicolumn{2}{|c|}{ 95\% CI for OR } \\
\hline & & & & & & Lower & Upper \\
\hline Gestational age & 1.141 & 0.311 & 7.631 & 0.005 & 2.131 & 1.009 & 3.617 \\
\hline Birth weight & 1.712 & 1.183 & 6.542 & 0.002 & 3.111 & 1.213 & 4.124 \\
\hline Multiple pregnancy & 1.818 & 0.216 & 5.864 & 0.02 & 2.354 & 1.712 & 4.619 \\
\hline Eclampsia & 0.256 & 0.277 & 0857 & 0.354 & 0.774 & 0.450 & 1.331 \\
\hline Sepsis & 2.394 & 0.315 & 2.560 & 0.002 & 2.483 & 1.799 & 3.752 \\
\hline RDS & 0.935 & 0.284 & 10.822 & 0.001 & 1.393 & 1.093 & 2.685 \\
\hline 02 supplementation & 1.921 & 0.265 & 52.597 & 0.000 & 6.380 & 4.063 & 11.479 \\
\hline Fetal distress & 1.264 & 0.243 & 27.160 & 0.000 & 3.540 & 2.201 & 5.695 \\
\hline Phototherapy & 0.252 & 0.260 & 0.943 & 0.332 & 1.287 & 0.773 & 2.141 \\
\hline Ventilation & 0.274 & 0.341 & 2.912 & 0.041 & 1.023 & 1.007 & 2.411 \\
\hline Blood transfusion & 1.256 & 0.277 & 0.857 & 0.354 & 0.774 & 0.450 & 1.331 \\
\hline Surfactant & 1.612 & 0.191 & 0.219 & 0.053 & 0.854 & 0.704 & 2.112 \\
\hline Anaemia & 1.254 & 0.5511 & 12.781 & 0.000 & 1.672 & 1.016 & 2.114 \\
\hline Thrombocytopenia & 0.462 & 0.234 & 0.982 & 0.056 & 0.891 & 0.678 & 1.412 \\
\hline
\end{tabular}

$\mathrm{p}<0.05$ = statistically significant; RDS — respiratory distress syndrome; $\mathrm{SE}$ — standard error; $\mathrm{OR}$ — odds ratio; $\mathrm{Cl}$ — confidence interval

any stage ROP in the SGA group was significantly higher than in the AGA group. The incidence of type 1 ROP in our study was $10.98 \%$. (33\% in the SGA group and $25 \%$ in the AGA group). Dhaliwal et al. [19], in their study, observed that SGA infants were not only prone to develop any stage ROP $(\mathrm{p}<0.01)$, but they were also prone to develop type 1 ROP ( $=0.01)$. Kavurt et al. [20] (28.2\% incidence of ROP in SGA) and Raj et al. [17] (40\% incidence of ROP in SGA) have also observed SGA as a significant risk factor for the development of ROP. A systematic review [21] concluded that SGA is a strong risk factor for the development of any stage as well as ROP needing treatment. The increased incidence of ROP in SGA infants is postulated to be due to intrauterine growth restriction. This makes the infants prone to changes in organ development because of fetal hypoxemia, nutrient restriction, and an altered endocrine environment [21]. These infants tend to be sicker, requiring a more extended stay in the NICU and maybe more supplemental oxygen. They also have lower insulin-like growth factor 1 (IGF1) levels which play an important role in the pathogenesis of ROP [23]. In addition, genetic factors also have been implicated [24, 25].

Lundgren et al. observed that infants born more mature but are growth restricted are more prone to develop ROP $[10,26]$. This is in concurrence with our observation that older SGA infants are more prone to develop ROP.
The problem unique to countries in the developing world is that these affected infants are far older and far heavier than the infants in the western world. One of the reasons for the same could be the poor survival rate of infants born less than 28 weeks in low to middle-income countries. In our study itself, there was only one infant with GA at 27 weeks and three born at 28 weeks GA in the AGA group, whereas, in the SGA group, there was only one infant born at 28 weeks of GA. Similarly, in our study in the SGA group, there were only three infants with weight less than 1000 grams (800, 900, and $945 \mathrm{~g}$, respectively), while in the AGA group, there were only two infants of less than 1000 grams (800 and $1000 \mathrm{~g}$, respectively).

On univariate analysis, the risk factors for ROP development in both the SGA and AGA groups were the same. On multivariate analysis, blood transfusion was noted to be a risk factor for the SGA group only. Similar findings were observed by Fortes Filho et al. [27].

The drawbacks of our study are the relatively small patient population and single center-based.

\section{CONCLUSION}

The incidence of ROP was higher in SGA infants compared to AGA infants in the present study. However, there was no difference in the risk factors and severity of ROP between the two groups. 


\section{REFERENCES}

1. Gilbert C, Foster A. Childhood blindness in the context of VISION 2020 — the right to sight. Bull World Health Organ. 2001; 79(3): 227-232, indexed in Pubmed: 11285667.

2. Dutta S, Raghuveer T, Vinekar A, et al. Can We Stop the Current Epidemic of Blindness From Retinopathy of Prematurity? Indian Pediatr. 2016; 53 Suppl 2: S80-S84, indexed in Pubmed: 27915311.

3. Zin A, Gole GA. Retinopathy of prematurity-incidence today. Clin Perinatol. 2013; 40(2): 185-200, doi: 10.1016/j.clp.2013.02.001, indexed in Pubmed: 23719304.

4. Vinekar A, Dogra MR, Sangtam T, et al. Retinopathy of prematurity in Asian Indian babies weighing greater than 1250 grams at birth: ten year data from a tertiary care center in a developing country. Indian J Ophthalmol. 2007; 55(5): 331-336, doi: 10.4103/0301-4738.33817, indexed in Pubmed: 17699940.

5. Shah PK, Narendran V, Kalpana N, et al. Severe retinopathy of prematurity in big babies in India: history repeating itself? Indian J Pediatr. 2009; 76(8): 801-804, doi: 10.1007/s12098-009-0175-1, indexed in Pubmed: 19802548.

6. Thakre SR, Deshmukh PA, Kalyanshetti G, et al. Incidence, Severity, and Risk Factors of ROP . Perinatology. 2017; 18(2): 50-55.

7. Project operational guidelines. Prevention of Blindness from Retinopathy of Prematurity in Neonatal Care Units. https://phfi.org/wp content/uploads/2019/05/2018-ROP-operational-guidelines.pdf (July 18, 2017.).

8. Honavar SG. Do we need India-specific retinopathy of prematurity screening guidelines? Indian J Ophthalmol. 2019; 67(6): 711-716, doi: 10.4103/ijo.IJO 973 19, indexed in Pubmed: 31124474.

9. Bal S, Ying GS, Tomlinson L, et al. Postnatal Growth and Retinopathy of Prematurity (G-ROP) Study Group. Association of Weight Gain Acceleration With Risk of Retinopathy of Prematurity. JAMA Ophthalmol. 2019; 137(11): 1301-1305, doi: 10.1001/jamaophthalmol.2019.3447, indexed in Pubmed: 31486831

10. Lundgren $P$, Kistner $A$, Hansen-Pupp I, et al. Small for gestational age as a risk factor for severe retinopathy of prematurity is dependent on gestational age at birth. Invest Ophthalmol Vis Sci. 2014; 55(13): 4580.

11. National Neonatology Forum, India. Evidence Based Clinical Practice Guidelines. New Delhi, 2010. http://www.nnfi.org/images/pdf/ nnf_cpg_consolidated_file-january102011.pdf (July 18, 2017).

12. Fenton $\overline{T R}, \mathrm{Kim} \mathrm{JH}$. A systematic review and meta-analysis to revise the Fenton growth chart for preterm infants. BMC Pediatr. 2013; 13: 59, doi: 10.1186/1471-2431-13-59, indexed in Pubmed: 23601190.

13. Tsai LY, Chen YL, Tsou Kl, et al. Taiwan Premature Infant Developmental Collaborative Study Group. The impact of small-for-gestational-age on neonatal outcome among very-low-birth-weight infants. Pediatr Neonatol. 2015; 56(2): 101-107, doi: 10.1016/..pedneo.2014.07.007, indexed in Pubmed: 25440777.

14. Shah PK, Prabhu V, Karandikar SS, et al. Retinopathy of prematurity: Past, present and future. World J Clin Pediatr. 2016; 5(1): 35-46, doi: 10.5409/wjcp.v5.11.35, indexed in Pubmed: 26862500.
15. Bowe T, Nyamai $L$, Ademola-Popoola D, et al. The current state of retinopathy of prematurity in India, Kenya, Mexico, Nigeria, Philippines, Romania, Thailand, and Venezuela. Digit J Ophthalmol. 2019; 25(4): 4958, doi: 10.5693/djo.01.2019.08.002, indexed in Pubmed: 32076388.

16. Sathar A, Abbas S, Nujum ZT, et al. Visual Outcome of Preterm Infants Screened in a Tertiary Care Hospital. Middle East Afr J Ophthalmol. 2019; 26(3): 158-162, doi: 10.4103/meajo.MEAJO_64_17, indexed in Pubmed: 31619904.

17. Latha NV, Raj $R$, Asha AV, et al. A comparative study of the incidence of retinopathy of prematurity between small-for-gestational-age and appropriate-for-gestational-age preterm babies in North Kerala. Kerala J Ophthal. 2017; 29(3): 197, doi: 10.4103/kjo.kjo 9417.

18. Fortes Filho JB, Valiatti FB, Eckert GU, et al. Is being small for gestational age a risk factor for retinopathy of prematurity? A study with 345 very low birth weight preterm infants. J Pediatr (Rio J). 2009; 85(1): 48-54, doi: 10.2223/JPED.1870, indexed in Pubmed: 19198736.

19. Dhaliwal CA, Fleck BW, Wright $E$, et al. Retinopathy of prematurity in small-for-gestational age infants compared with those of appropriate size for gestational age. Arch Dis Child Fetal Neonatal Ed. 2009; 94(3): F193-F195, doi: 10.1136/adc.2008.143552, indexed in Pubmed: 18786959.

20. Kavurt S, Özcan B, Aydemir O, et al. Risk of retinopathy of prematurity in small for gestational age premature infants. Indian Pediatr. 2014; 51(10): 804-806, doi: 10.1007/s13312-014-0506-9, indexed in Pubmed: 25362011.

21. Razak A, Faden M. Association of small for gestational age with retinopathy of prematurity: a systematic review and meta-analysis. Arch Dis Child Fetal Neonatal Ed. 2020; 105(3): 270-278, doi: 10.1136/ archdischild-2019-316976, indexed in Pubmed: 31326921.

22. McMillen IC, Adams MB, Ross JT, et al. Fetal growth restriction: adaptations and consequences. Reproduction. 2001; 122(2): 195-204, doi: 10.1530/rep.0.1220195, indexed in Pubmed: 11467970.

23. Smith LEH. IGF-1 and retinopathy of prematurity in the preterm infant. Biol Neonate. 2005; 88(3): 237-244, doi: 10.1159/000087587, indexed in Pubmed: 16210846.

24. Bizzarro MJ, Hussain N, Jonsson B, et al. Genetic susceptibility to retinopathy of prematurity. Pediatrics. 2006; 118(5): 1858-1863, doi: 10.1542/peds.2006-1088, indexed in Pubmed: 17079555.

25. Drenser KA, Dailey W, Vinekar A, et al. Clinical presentation and genetic correlation of patients with mutations affecting the FZD4 gene. Arch Ophthalmol. 2009; 127(12): 1649-1654, doi: 10.1001/ archophthalmol.2009.322, indexed in Pubmed: 20008721.

26. Lundgren $P$, Kistner A, Andersson EM, et al. Low birth weight is a risk factor for severe retinopathy of prematurity depending on gestational age. PLoS One. 2014; 9(10): e109460, doi: 10.1371/journal. pone.0109460, indexed in Pubmed: 25330287.

27. Fortes Filho JB, Eckert GU, Valiatti FB, et al. The influence of gestational age on the dynamic behavior of other risk factors associated with retinopathy of prematurity (ROP). Graefes Arch Clin Exp Ophthalmol. 2010; 248(6): 893-900, doi: 10.1007/s00417-009-1248-6, indexed in Pubmed: 20016911. 